\title{
Research on the Formation Mechanism of Cross-border E-commerce Payment Risk
}

\author{
Guan Xiaoyong ${ }^{1}$, Ren Jie ${ }^{2}$ \\ Alibaba Business School, Hangzhou Normal University \\ Hangzhou, Zhejiang
}

\begin{abstract}
Cross-border payment is an important part of cross-border e-commerce development, the risks arising from the payment process will have a huge impact on the completion of cross-border trade. Payment risk research is also an important part of the risk security mechanism. Through literature and on-site investigation and research, there are many risks in the cross-border payment, such as liquidity risks in the process of cross-border payment, irregular development of payment market, loopholes in information technology, lag and gap in payment laws, and poor adaptability of laws and payment markets. Then, based on the characteristics of China's economic development and the development needs of cross-border e-commerce, suggestions for improvement are proposed from aspects of market, credit, technology and law.
\end{abstract}

Keywords-cross-border e-commerce; payment risk; formation mechanism

\section{INTRODUCTION}

In recent years, cross-border e-commerce has developed rapidly. As an indispensable settlement support - cross-border payments should also be booming. The relevant theoretical and practical issues of cross-border payment have become the focus of academic circles. Throughout the existing research, the academic community mainly focuses on the manifestations of various risks in the cross-border payment process. Du Xin-miao (2019) believes that the current cross-border payment risk is mainly reflected in the information leakage of transaction entities, the illegal flow of cross-border funds and the management of reserve funds [1]. Xia Lei (2007) pointed out that there are funds, information security and legal status of cross-border payment. And the scope of business is not clear and other issues. However, the systematic study of the mechanism of cross-border payment risk formation has not been published in the literature. The description of risk is limited to the analysis of performance patterns. The research subjects and research perspectives are relatively simple. The existing risk research does not form a complete theoretical system, and it is impossible to establish a security system for risk avoidance. This paper attempts to use the method of qualitative analysis to summarize the risks in the cross-border payment process into four aspects: credit, market, technology and law. Based on the information obtained from the literature and on-site investigation, the main forms of cross-border payment risk and its formation mechanism are analyzed and characterized, in order to provide valuable reference and clues for future research in this area.

\section{CLASSIFICATION AND MORPHOLOGY OF CROSS-BORDER E-COMMERCE PAYMENT RISK}

\section{A. Definition of cross-border e-commerce payment risk}

China's foreign exchange administration gives the definition of cross-border e-commerce is that the two parties belonging to different countries and regions use the e-commerce platform to complete the international commercial activities of order delivery, payment settlement and logistics distribution [2]. Cross-border payment is the transfer of monetary credits that occurs during the completion of cross-border transactions. Cross-border payment risk is the possibility of loss due to uncertain factors in the payment process of cross-border trade.

\section{B. Classification and form of cross-border e-commerce payment risk}

1) Risk classification of cross-border e-commerce payment methods

\section{a) Credit risk}

Credit risk refers to the possibility of contract losses caused by the non-performing or incomplete performance of contractual obligations by a party to the transaction in the process of cross-border trade payment, that is, the risk of default.

\section{b) Technical risk}

Possibility due to imperfect payment processes, system and technology deficiencies, and losses due to external events. According to the source of occurrence, it can be divided into endogenous and exogenous risks.

\section{c) Market risk}

Cross-border payment market risk refers to the possibility of loss due to reasons such as price, exchange rate changes, and lack of liquidity.

\section{d) Legal Risk}

Legal risk refers to the possibility of loss due to lack of system, lag, regulatory chaos, ambiguous responsibility and legal system differences caused by cross-border trade characteristics.

2) Performance of cross-border e-commerce payment risk a) Credit risk

(1) Pay the credit risk generated by itself. Cross-border electronic payment is a financial business that breaks through time and space restrictions and virtualizes borderless. The 
distribution is global, and political and economic differences lead to increased difficulty in risk control [3]. The risk that the cross-border payment system is incompatible with the client terminal software and is not synchronized with the bank's internal system.

(2)Pay the credit risk of the participants. Commercial banks lack scientific liquidity management, and improper investment and loans cannot meet the payment requirements. The cost of canceling a trade order between the buyer and the seller is low and the risk of payment is increased. The payment platform uses information asymmetry to conduct illegal operations, misappropriate the deposited funds that are stuck in the platform, and cannot complete the risk of liquidity risk arising from the task of transferring funds.

\section{b) Technical risk}

(1)Endogenous risks. The network environment is unstable, the characteristics of the computer itself are flawed, the security of the payment system is poorly managed, the data is distorted, the channel congestion, the system paralysis, etc. affect the information transmission, and the transaction cannot be completed normally.

(2)Exogenous risks. Staff negligence or operational skills are immature, and operational vulnerabilities caused by customer misuse. Internal employees use their duties, criminals use network viruses for illegal intrusion, and steal user data to transmit false payment orders and other threats to financial security.

\section{c) Market risk}

(1)Competition risk. The number of payment institutions has increased sharply, but most of the service projects are consistent, and the homogenization phenomenon is serious, affecting the quality of customer service. The polarization of the payment platform is serious. The fierce competition in the payment market, the narrow profit margin, and the unscrupulous profitability status are likely to lead to insufficient capital turnover of payment institutions [4] and even mergers and acquisitions in the industry, and the financial market order has been destroyed.

(2)Exchange rate risk. Cross-border trade involves different trading currencies. Changes in exchange rates affect the purchasing power of funds, resulting in insufficient exchanges, etc., causing loss of economic interests of the trading parties and affecting the enthusiasm of cross-border transactions. The large-scale precipitation of the RenMinBi abroad cannot play the role of carrier currency, and it cannot form an orderly cross-border RenMinBi cycle, resulting in loss of economic efficiency and affecting financial stability [5].

\section{d) Legal risk}

(1)The gap and lag of the legal system. At present, the highest legal requirement for cross-border payment business in China is the Regulations of the People's Republic of China on Foreign Exchange Control. The regulations for the operation of foreign exchange settlement and sales of non-financial institutions are too simple. They do not involve electronic payment and cross-border payment related content, and lack direct administrative regulations support [6]. Moreover, the level of laws and regulations is low, and management regulations are mostly issued in the form of notifications. Financial laws and regulations cannot adapt to the development of emerging cross-border e-commerce payment services, and traditional foreign exchange management mechanisms face new challenges.

(2)The powers and responsibilities are not clear and the division is chaotic. China has no unified management standards for the degree of business compliance, business processes, and risk control of payment institutions. The information reported by cooperative banks and payment institutions to the SAFE has not yet matured [7]. The legal status of cross-border payment institutions is not clear, the business is in the gray area of supervision, and there are difficulties in the identification of responsibilities. Supervision requires multi-sector cooperation, which is more likely to result in unclear powers and inefficient supervision.

\section{ANALYSIS OF THE FORMATION MECHANISM OF CROSS-BORDER E-COMMERCE PAYMENT RISK}

\section{A. Credit risk}

The overall credit status of the society is not good. Participants in the cross-border e-commerce industry lack integrity, credit awareness, and a weak sense of rules. They are driven by interests to violate the ethical norms and legal requirements to produce untrustworthy behavior. In order to promote the development of cross-border payment services in China, the provision of loose access thresholds has led to uneven qualifications of payment institutions. Cross-border business has developed rapidly, and huge transaction volume has caused huge amounts of funds to settle. The payment institution uses the dominant position in market information, capital flow, and technology maturity to conduct illegal operations, and unreasonably invests in the deposited funds to generate liquidity risk.

China's credit legislation is lacking, the act of dishonesty is not legally bound, the punishment of morality is too low, legal sanctions and moral trials cannot be organically combined, and a reasonable mechanism of dishonesty cannot be formed ${ }^{[8]}$. International coordination mechanisms for synergy have not yet been established, information cannot be shared, and there is no uniform standard for regulatory measures and penalties. Fragmented management provides convenience for cross-border payment of crime. The management rules of payment institutions are too general and lack of operability, and they are always outside the regulatory system of financial institutions, and supervision lacks coercive power.

\section{B. Technical risk}

Cross-border payment services rely on the Internet. The particularity of the network environment leads to insufficient information security. The cyber attack methods are changing with each passing day, and cross-border payment security faces challenges. The design of cross-border payment electronic information transmission system and electronic information processing system is unreasonable, and there are program loopholes. The payment institution verification system is in the initial stage of construction, the customer data review procedures are not perfect, the information verification authenticity requirements are low, and the audit methods are 
not strict. Payment agencies are not paying enough attention to cybercrime issues, security defense measures are missing, databases are vulnerable to attacks, and customer funds and information security are not guaranteed.

The payment platform is committed to providing personalized services to attract customers, the operation process is not uniform, the staff's cognitive and operational capabilities are limited, and the collection, analysis and processing of relevant information are subject to individual capabilities, and it is difficult to verify the authenticity of the information. The importance of making accurate judgments can easily lead to errors in business activities, resulting in operational risks [9]. People have limited rationality, and online fraud caused by moral hazard affects the security and stability of the payment system.

\section{Market risk}

China has implemented policy inclination to support the development of cross-border trade, with low thresholds. The good development momentum has attracted a large number of payment institutions, resulting in homogenization of services. The advantage of profit-seeking makes it divide the market share. The dominant position institutions use monopoly means to set up industrial barriers. The disadvantaged status institutions use illegal means to obtain market survival status, gradually form vicious competition, and the payment market is increasingly polarized. At the same time, there is a lack of market exit mechanism, and violations of regulations and disorderly operations are frequent and the market is chaotic.

Cross-border trade involves many countries and regions, and political stability and economic development in these regions will affect exchange rate changes, which in turn will affect bilateral settlement. In the process of cross-border payment fund transfer, due to logistics delay, customs security inspection, infrastructure confirmation and many other factors, affecting the timeliness of the payment process, the exchange rate changes with the market changes, directly affecting the actual purchasing power of funds, causing losses to cross-border transaction participants.

\section{Legal risk}

The rapid development of cross-border payment industry in recent years has put forward higher requirements for legal supervision. China's cross-border trade, electronic payment, and online banking payment risk supervision system are all in their infancy, leading to the legislation of cross-border electronic payment in China. In the early stages, when encountering risks, we can only rely on the large framework of China's business trade regulations and reference to international rules. At present, we have not established a complete legislative system.

The People's Bank of China promulgated the Measures The Administration of Payment Services for Non-Financial Institutions in 2010, which stipulates that third-party payment institutions are intermediary non-financial institutions engaged in payment services, but their business scope includes providing credit guarantees for both parties to the transaction and opening virtual Accounts, absorption of deposits and loans, etc., are inconsistent with their nature, resulting in their business supervision in a gray area, lack of professional supervision and regulatory restrictions, and the identification of responsibilities is difficult. Cross-border electronic payment has two characteristics of e-commerce and cross-border payment. Its special nature requires joint enforcement by the regulatory authorities. At present, China's cross-border payment service has a single supervision mode, and there is no detailed regulation on the coordination of multi-sector supervision. Linkage, it is difficult to form effective supervision

\section{CROSS-BORDER E-COMMERCE PAYMENT RISK CONTROL METHOD AND PATH MANAGEMENT}

\section{A. Accelerate the construction of cross-border e-commerce payment credit system.}

Enhance the awareness of Chinese people's credit. The company establishes customer credit files and forms a credit evaluation mechanism for customers. Encourage the payment of self-discipline in the industry, strictly review the transaction participants and transaction content, and report the transaction materials with huge transaction amount or doubts to the State Administration of Foreign Exchange in time to cooperate with the review of relevant departments. The government led the establishment of a social credit system to form a credit database covering users, payment institutions and banks. The user information, bank deposit and loan information, payment agencies pay taxes and other information are integrated and classified, and are continuously updated to gradually realize information sharing and online query. Establish a credit evaluation agency to calculate and analyze database information, evaluate the credit status of users and payment institutions, improve the information disclosure system, establish a system of trustworthiness incentives and dishonesty, and improve the efficiency of market supervision ${ }^{[10]}$. Drawing on the development experience of credit institutions in developed countries, the development scale and marketization degree of domestic credit institutions will be improved, and the rapid development of cross-border payment will be adapted.

\section{B. Improve the level of supervision technology.}

Improve the adaptability of payment risk supervision, information transmission technology and payment services. Increase investment in anti-hacking and Trojan horse technology research and development. Provide vocational training and moral education to the staff of the payment institution, improve the quality and learning ability of the staff, reduce the risk accidents caused by operational errors and moral hazard, and repair the safety technology loopholes in the operation process to improve the frequency of technological innovation.

\section{Strengthen risk legal supervision.}

Fill in the gaps in rules and regulations on non-financial institutions, determine the clear assessment criteria and obligations of non-financial institutions, and formulate measures to reduce risks such as transaction defaults, risk preparation arrangements and risk apportionment, and promote the sound development of the financial order. 
Establish a linkage supervision mode, jointly develop various regulatory standards, establish an information database, and use Internet technology to realize information sharing and update in real time, and accept and check at any time. Secondly, the regulatory body is clearly defined, and the regulatory responsibility is reasonably divided into specific departments and even specific individuals, and the division of responsibilities is clearly defined. Strengthen international regulatory cooperation, analyze the differences in regulatory technologies, advantages and disadvantages, and adaptability of countries, and choose more appropriate regulatory technologies. Promote the exchange and cooperation of payment service risk supervision and payment service legislation, and reach the link between payment legislation and international payment rules.

\section{Strengthen third party payment reserve management}

In 2011, the Interim Measures for the Depository of Deposits by Clients of Payment Organizations stipulated that the reserve fund was the part of the funds that were retained by the payment platform and the entrusted payment institution of the user due to the difference in trading time ${ }^{[11]}$. The reserve fund cooperative bank and the depository bank respectively Responsible for the deposit, transfer, information reporting and provision of funds for centralized deposit and collection. However, the information disclosure system for the provision payment system has not been established, and the transparency of users' access to information and law enforcement supervision is insufficient, which is not conducive to rights protection.

First of all, it should provide a basic legal basis for the management of the provision, and clarify the provision of the reserve and its interest and the legal relationship of the management party. Break the old concept, rationalize the use of the reserve fund by the payment institution, and improve the circulation rate and utilization rate of the funds. Clearly define the scope of application of the provision, and select projects with large liquidity and low risk to invest. Secondly, the establishment of the supervision system of the People's Bank of China as the core, the China Banking Regulatory Commission, and the Ministry of Information Industry joint law enforcement ${ }^{[12]}$. The bank has the supervision of the reserve fund account bank and the reporting authority of the higher-level supervision department, and the CBRC assumes the responsibility of supervising the commercial bank. The Ministry of Information Industry plays a huge role in promoting information technology construction and maintaining information security. Clarify the division of responsibilities among departments and reduce the shirking and multi-management in the law enforcement process.

\section{CONCLUSION}

The update of Internet technology and the rapid development of the economy have given birth to cross-border e-commerce. Economic globalization has pushed the development of cross-border e-commerce to a new high. China's cross-border e-commerce development momentum is rapid, which has impacted China's current legal system, economic market construction, social credit system construction and information technology development. The payment risk in cross-border e-commerce transactions is particularly prominent. As an important part of the trade process, payment has a great impact on the integrity of the transaction process. Therefore, from reducing the risk of payment as a starting point to improve the legal and regulatory system for cross-border e-commerce, strengthen supervision, improve supervision, build a reasonable economic market order, strengthen the management of payment provisions, and improve the construction of a social credit system. The healthy development of e-commerce is of great significance.

\section{ACKNOWLEDGMENT}

Guan Xiaoyong, Professor, Alibaba Business School, Hangzhou Normal University, doctor.(Hangzhou, Zhejiang 311100).

Ren Jie, Master of Alibaba Business School, Hangzhou Normal University.(Hangzhou, Zhejiang 311100).

\section{REFERENCES}

[1] Yang Song, Guo Jinliang. Research on Legal Issues of Risk Supervision of Cross-border Electronic Payment Services [J].Research on the Rule of Law, 2013(02): 64-72.

[2] Zhou Liping, Yu Pinxian. Status Quo, Risk and Supervision Countermeasures of Cross-border E-commerce Payment [J]. Shanghai Finance, 2016(05):73-78.

[3] Shi Zhiqiang. Government supervision of third-party online payment risk research [D]. Yanshan University, 2015

[4] Yang Song, Guo Jinliang. Research on Legal Issues of Risk Supervision of Cross-border Electronic Payment Services [J]. Rule of Law, 2013(02): 64-72.

[5] Ye Huawen, Yan Yanchang. Research on the problems and countermeasures of third-party cross-border payment [J]. E-commerce, 2014(09):37-40

[6] Chen Yu. Research on RMB cross-border payment system [D]. Jilin University, 2017.

[7] Hu Bo. The Idea of Establishing China's Unified Cross-border Payment System [J].Financial Accounting,2010(02):19-23.

[8] E Libin, Huang Yongwen. New Ways of International Trade: The Lates Research on Cross-border E-commerce [J]. Journal of Dongbei University of Finance and Economics, 2014(02): 22-31.

[9] Su Changlei. Looking at RMB cross-border payment from international experience [J]. Banker, 2016(04): 98-102.

[10] Yang Song, Guo Jinliang. Research on Legal Issues of Risk Supervision of Cross-border Electronic Payment Services [J]. Rule of Law Research, 2013(02): 64-72.

[11] Li Cheng, Chen Hengyou. Third Party Payment Innovation and Money Laundering Risk Prevention and Control [J]. Times Finance, 2016(11): 203-206.

[12] Sun Yi. Research on operational risk of commercial banks [D]. Southwestern University of Finance and Economics, 2010 